\title{
AS MUDANÇAS DO SUBSTANTIVO NOS TEXTOS CONSTITUCIONAIS BRASILEIROS
}

\author{
Natália Martins Gonçalves ${ }^{1}$ \\ Aline Espíndola de Borba ${ }^{1}$ \\ Fernanda Cizescki ${ }^{2}$
}

\section{INTRODUÇÃO}

A constituição de um país é a lei máxima que descreve os princípios e valores que direcionam as ações do governo na política, na economia, no campo da justiça, da administração pública e das diretrizes sociais e culturais. Somado a isso, a constituição estabelece os princípios e valores que norteiam os direitos individuais e coletivos, além de ser a base para a proposição de quaisquer outras leis. Sendo assim, as palavras escritas nos textos constitucionais são especialmente carregadas de significados.

Ao se estudar as palavras na escrita de uma constituição específica podese afirmar que este objeto está dentro do campo de estudo da linguística histórica. Como afirma Faraco (1991, p.57), "[...] as línguas mudam no eixo do tempo e a linguística histórica ocupa-se, então, fundamentalmente com as transformações das línguas no tempo [...]". E as palavras escritas na constituição de um determinado ano expressam o significado conforme as concepções da linguagem naquele período.

A análise do significado e do uso das palavras em um dado momento histórico remete à ideia de que a língua não é estática e atemporal, mas se transforma ao longo da história e nas diversas comunidades de fala. Essa perspectiva aponta que o estudo da linguagem pode ser desenvolvido em uma dimensão diacrônica, ou histórica, que admite que as línguas podem mudar, se transformar no tempo e a sincrônica, ou seja, aquela que considera a língua com mudança lenta e gradual. Faraco (1991, p.60) explica estas duas abordagens da seguinte forma: "na primeira, o centro das atenções são as mudanças por que passa uma língua no tempo; na segunda, não as características da língua vista como sistema estável no espaço de tempo aparentemente fixo."

\footnotetext{
${ }^{1}$ Acadêmica do Curso de Letras Habilitação em Língua Portuguesa da Universidade do Extremo Sul Catarinense (UNESC) E-mail: ngo@unesc.net

${ }^{2}$ Professora do Curso de Letras Habilitação em Língua Portuguesa da Universidade do Extremo Sul Catarinense (UNESC) E-mail: fcz@unesc.net
} 
Considerando a análise das mudanças dos substantivos dos textos constitucionais brasileiros de 1824 e 1988, pode-se afirmar que este estudo comparativo deve ser fundamentado na abordagem diacrônica, pois as palavras sofreram transformações na sua significação e no seu contexto nesses dois momentos históricos.

Vale ressaltar, que este estudo comparativo de textos constitucionais examina as mudanças da língua escrita e formal, por ser um texto da área jurídica. Portanto, como escreve Faraco (1991), essas mudanças poderão ser mais conservadoras quando comparadas com a língua falada e, assim, as inovações ocorridas apareçam com menor intensidade.

Bentes e Mussalim (2007, p.81) afirmam que "toda língua falada no mundo está em constante processo de mudança." Diversos autores alertam que as mudanças ocorrem de forma gradual e "qualquer parte da língua pode mudar, desde aspectos da pronúncia até aspectos de sua organização semântica e pragmática" (FARACO, 1991, p.20). Sendo gradual, as mudanças não são sentidas pela comunidade de fala, no mesmo momento em que elas ocorrem e os falantes, por conseguinte, não processam essas mudanças de forma consciente e de imediato (BENTES; MUSSALIM, 2007). Além disso, essas mudanças não afetam todo o sistema linguístico com a mesma intensidade (BENTES; MUSSALIM, 2007).

Nesse sentido, esta investigação objetiva identificar as mudanças do significado e do uso do substantivo, campos de estudo da semântica e da pragmática, nos textos constitucionais de duas constituições brasileiras em dois momentos históricos, separados por um tempo de 300 anos de história (1824 e 1988) e dos regimes políticos e de governos distintos: o Império e a República Federativa. Especificamente, busca-se identificar os substantivos da Constituição de 1824 que se repetem na Constituição de 1988; verificar a incidência de mudanças semânticas e pragmáticas que ocorreram nos substantivos que se repetem nas duas constituições; analisar a frequência e os tipos de mudança semântica e pragmática.

Os resultados esperados desse estudo centram-se na verificação da incidência de mudanças do significado e do uso das palavras (substantivos) nos textos constitucionais, bem como na análise das mudanças mais frequentes. Buscase ainda, entender as concepções do significado do substantivo nos textos constitucionais a fim de contribuir para o estudo da linguística histórica, através de textos oficiais do Estado Brasileiro. 


\section{METODOLOGIA}

A presente pesquisa seguiu uma abordagem qualitativa para a coleta e a análise dos dados. Teve como finalidade ser descritiva, levando em conta 0 processo de analisar e descrever as mudanças do significado e uso dos substantivos de textos constitucionais brasileiros. Neste contexto, os meios de investigação utilizados foi a pesquisa bibliográfica. Considera-se bibliográfica devido à consulta a acervos com temas relacionados à linguística histórica, à semântica e à pragmática. A coleta de dados foi feita no acervo de livros e periódicos disponibilizados na biblioteca da Universidade do Extremo Sul Catarinense (UNESC), textos disponibilizados em aula pela disciplina de "Morfologia e Sintaxe Histórica", ferramentas de busca da internet, como o Google acadêmico, Scielo, DOAJ, que disponibiliza dissertações, teses e artigos científicos e Webesites oficiais, como o da base de dados de textos legais do Palácio do Planalto.

O presente estudo está limitado à análise dos Títulos de $1^{\circ}$ ao $3^{\circ}$ das Constituições brasileiras de 1824 e 1988. Propõe-se identificar os substantivos da Constituição de 1824 que se repetem na Constituição de 1988. Além disso, os substantivos identificados na Constituição de 1824 foram usadas para a realização do processo de busca na Constituição de 1988 para verificar se os mesmos se repetiam nessa Constituição. Os resultados esperados desse estudo centram-se na verificação da incidência de mudanças do significado e do uso das palavras (substantivos) nos textos constitucionais, bem como na análise das mudanças mais frequentes.

\section{REFERENCIAL TEÓRICO}

A língua portuguesa se organiza em diferentes estruturas como: a fonética, a fonologia, a morfologia, a sintaxe, a semântica e a pragmática e essas estruturas não estáticas, mas sofrem mudanças constantes e graduais através da história dessa sociedade. Muitas dessas mudanças podem ser verificadas nos diferentes registros da língua e em documentos oficiais históricos, guardados nas bases de dados do Estado brasileiro. Para poder examinar com propriedade científica esses registros, faz-se necessário a revisão bibliográfica das teorias pertinentes para poder ter suporte aos resultados encontrados,bem como suas análises. 


\section{LINGUÍSTICA HISTÓRICA}

Toda língua viva permanece em processo constante de mudança e adaptação à sociedade em que está inserida, pois a sociedade evolui. As mudanças da língua constitui o objeto de estudo da Linguística Histórica. Bentes e Mussalim (2007, p.77) escreve: "A Linguística Histórica estuda os processos de mudança das línguas no tempo." O estudo da linguística histórica é uma ciência, pois possui um objeto delimitado (as mudanças da língua na história), como também se utiliza de um método científico para confirmar refutar os resultados alcançados no estudo.

Martin (2003, p. 136) afirma que "toda língua é um receptáculo da história cultural". O autor ressalta que, para entender a sociedade atual, faz-se necessário um visão histórica da cultura dessa sociedade e, o mesmo, pode ser considerado para a linguística histórica. Essa relação é importante para se compreender como o ser humano constrói a sua identidade e reconhece a sua origem.

De acordo com Martin (2003, p.135), "Enquanto uma língua permanece viva, ela não deixará de se transformar, de se adaptar às necessidades de uma comunidade que também evolui.[...]". Ainda segundo o autor, além da língua estar sempre em mudança ela está ligada com a história da sociedade daquele determinado período.

\section{Orientações teóricas da linguística histórica}

A linguística histórica se desenvolveu como ciência no Século XIX. Ao longo dos últimos dois séculos a linguística histórica desenvolveu diferentes orientações teóricas e vertentes metodológicas. Faraco (1991) escreve que há três vias para estudo histórico das línguas: estudar o passado para reconstruir o passado (método comparativo); estudar o passado para entender o presente (neogramáticos, teoria gerativista); estudar o presente para iluminar o passado (teoria da variação).

Baseado em evidências apontadas no final do Século XVIII de que as línguas apresentava certo padrão na sua estrutura e certas semelhanças regulares entre algumas línguas, como o sânscrito, o latim e o grego, linguistas do Século XIX desenvolveram um método científico para estudar este problema proposto, testar a sua veracidade e generalizar para o estudo de outras línguas. Assim, foi proposto o método comparativo. O método comparativo foi utilizado para verificar o parentesco entre as línguas. Esse parentesco entre as línguas pode ser verificado pelos 
padrões das estruturas fonéticas e fonológicas, das estruturas gramaticais e do vocabulário, pelas mudanças de significado e do seu uso.

Para se entender essas vertentes metodológicas teóricas, precisa-se entender os conceitos de sincronia e diacronia. A sincronia faz um recorte na história e estuda as mudanças da língua na sua estrutura formal, interna. Já a diacronia estuda as mudanças da língua no seu movimento histórico. considerando a regularidade dos padrões, a língua muda e se transforma através da história, como por exemplo, por analogia e por empréstimo. Os comparativistas estudam a língua baseadas na diacronia. Os neogramáticos e Saussure afirmam que para se estudar as mudanças da língua tem-se que estabelecer pelo menos dois pontos sincrônicos na história.

De acordo com Faraco (1991, p.15):

[...] a diretriz sausurriana de que a análise sincrônica precede sempre a diacrônica, na medida em que só podemos comparar se temos a descrição de pelo menos dois estados de língua reforçou o tipo de estudo cujo objetivo é descrever sincronicamente um determinado estágio da história duma língua: o estudioso se fixa num momento do passado e, tornando-se estaticamente, descreve-o com base nos documentos escritos de que se dispõe, criando assim, condições para um posterior estudo diacrônico.

O estruturalismo é uma forma de trabalhar com signos, tendo por base a linguística de Saussure. No estruturalismo de Saussure encontramos como essencial a criação do objeto de estudo, unindo o significante (imagem acústica) ao significado (conceito), ou seja, não há significante sem significado e vice-versa, pois segundo Fiorin (2010, p.58) "[...] o significante sempre evoca um significado, enquanto o significado não existe fora dos sons que veiculam."

Saussure (2004, p. 80) afirma que:

Propomo-nos a conservar o termo signo para designar o total e a substituir conceito e imagem acústica respectivamente por significado e significante; estes dois termos têm a vantagem de assinalar a oposição que os separa, quer entre si, quer do total que fazem parte.

Segundo Ducrot (1971, p.16), “[...] no signo, o que há de novo não é o significado, mas a sua relação com o significante [...]". Saussure (1969, p. 130) dizia que "Filósofos e linguistas sempre concordam em reconhecer que, sem o recurso 
dos signos, seriamos incapazes de distinguir duas ideias de modo claro e constante."

Saussure não foi o criador do termo "estruturalista". Segundo Ducrot (1971, p. 55) o papel de Saussure foi "o de ter reencontrado, e, sobretudo ter podido impô-lo, após o êxito impressionante da gramática comparada."

\section{Mudanças da língua}

As línguas sofrem mudanças ao longo do tempo, apesar de ocorrer de um forma lenta, essa mudança é que constrói o objeto de estudo da Lingüística Histórica. Como cita Faraco (1991, p.9) "[...] as mudanças lingüísticas, embora ocorrem continuamente, se dão de forma lenta, o que faz com que só excepcionalmente percebamos esse fluxo histórico no nosso cotidiano de falantes."

Além de lenta, essas mudanças muitas vezes não são percebidas pelos falantes. Faraco (1991) considera que os falantes só percebem a mudança em sua língua, quando realizam a leitura de textos antigos de sua língua, por exemplo. É correto afirmar que o processo de mudança na língua, está relacionada com diversos fatores sociais, que podem acelerar ou retardar o processo de mudança. $E$ como afirma Faraco (1991, p.20): "Qualquer parte da língua pode mudar, desde aspectos da pronúncia até aspectos de sua organização semântica e pragmática."

É evidente que a língua muda continuamente, porém, por alguns motivos a comunidade de fala não percebe. Diversos fatores podem justificar esta falta de percepção imediata das mudanças, por exemplo: devido ao processo ser muito lento, passando por gerações que talvez só perceberão após gerações; essas mudanças ocorrem na estrutura das palavras, podendo modificar o seu significado. Faraco (1991, p.10) escreve que "[...] ocorrem modificações em sua forma, função e/ou significado. "

Vale ressaltar que a língua escrita é mais conservada que a língua falada. Vários fatores justificam essa afirmação, como: a escrita é mais douradora que o som; a escrita está ligada ao contexto social. Porém, Faraco (1991, p. 15) descreve "[...] que nem todas as diferenças entre fala e escrita são sinais de mudança; boa parte é simplesmente decorrente de características próprias da oralidade em oposição àquelas próprias da escrita."

Lyons (1987, p. 196) afirma que: 
A principal contribuição que os estruturalistas e os funcionalista fizeram para a linguística histórica está na sua insistência de que cada mudança postulada em um sistema linguístico tem que ser avaliada em termos de suas implicações para o sistema com um todo.

A parti da afirmação de Lyons (1987) podemos dizer que o estruturalismo analisa a mudança como parte das mudanças sistêmicas, tal como o contexto e o significado das palavras.

Essas mudanças de contexto, significado e uso das palavras são analisados dentro do campo de estudo da semântica e da pragmática.

\section{A Mudança semântica}

Lyons (1987) afirma que o estudo do significado está no campo da semântica. Fiorin (2004, p.144) ressalta que " a questão do significado daquilo que se diz constituiu uma interrogação permanente dos estudos sobre a linguagem desde seus primórdios." Portanto, o estudo da significação já era uma preocupação dos estudiosos nas épocas antigas, como são Tomás de Aquino, e continua nas abordagens dos estudos linguísticos da era em curso. Faraco (1991) defende que as mudanças semânticas são objeto de discussão da linguistica histórica, tratada na perspectiva do processo de mudança e alteração do significado da palavra.

Bentes e Mussalim (2007, p.89) escreve que "mudança semântica são as mudanças do significado das palavras (ou vocabulário) de uma língua". Faraco (1991) explica que o processo de mudança semântica pode restringir o significado da palavra, como também essas mudanças podem ampliar o significado da palavra. Por exemplo, no caso da palavra "território", abordada na Constituição de 1824 no sentido de "área de extensão sob o controle do Estado e de outras entidades políticas" e na Constituição de 1988 amplia o seu significado, adicionando "unidade da federação" (MAGDALENO, 2005, p.120).

Lyons (1981, p.133) ressalta que na visão tradicional "os significados são ideias ou conceitos que se podem transferir da mente do falante para a mente do ouvinte [...]". Porém, Mussalim e Bentes (2000) alertam que a definição do objeto da semântica é bastante controverso entre os diversos autores que estudam o tema. Existem aqueles como Moura (2000) que enfatiza que a fronteira entre a semântica e a pragmática é muito fluída e essa fronteira é normalmente traçada a partir da noção de contexto. Bentes e Mussalim (2007, p.91) afirmam que a mudança 
semântica por contato semântico "[...] adquire um outro significado a partir de um contexto específico."

Considerando o estudo proposto, a noção de contexto pode ser observada no uso das palavras nas Constituições de 1824 e de 1988. Como exemplo, o contexto que a palavra "religião" aparece na constituição de 1824 está relacionada ao uso da religião do ponto de vista do Império, como religião oficial, que poderia ser professada livremente, ter um templo com forma exterior específica para os cultos religiosos. No caso da constituição e 1988, a palavra religião se transforma para uma locução substantiva: "culto religioso" e é usada por grupos que se reúnem e que se autodenominam como parte desta religião, sem a necessidade de ser oficializada pelo Estado ou ter um templo com característica arquitetônica particular. O mesmo se pode afirmar com relação à palavra "templo" que é usada na constituição de 1824 como sinônimo de um tipo específico arquitetônico de construção, sendo que na Constituição de 1988 se relaciona ao local usado para os cultos religiosos, independentemente de uma forma arquitetônica definida.

\section{Mudança pragmática}

Fiorin (2004, p.161) destaca que:

[...] a pragmática é a ciência do uso linguístico, estuda as condições que governam a utilização da linguagem, a prática linguística. Um dos domínios de fatos linguísticos que exigem a introdução de uma dimensão pragmática nos estudos linguísticos é a enunciação, ou seja, o ato de produzir enunciados, que são realizações linguísticas concretas. Essa exigência se dá, porque há certos fatos linguísticos, que só são entendidos em função do ato de enunciar.

Nem todo o contexto é considerado pragmático; poderá ser caso esteja considerado o que estiver ligado a uma definição. Nesse sentindo o "contexto" não define a separação da pragmática com a semântica. Ao descrever que a semântica estuda o significado das palavras, muitas vezes precisa-se saber o contexto, para só assim poder avaliar o que foi falado.

Como ressalta a citação de Moura (1999), a pragmática está vinculada ao contexto, considerando na análise a crença dos interlocutores. Já no caso da semântica, o contexto para Moura (1999, p.95) pode ser assim explicado: "[...] conteúdo semântico de um enunciado corresponde à forma como ele afeta o contexto em que foi produzido." 


\section{AS MUDANÇAS DO SUBSTANTIVO NOS TEXTOS CONSTITUCIONAIS BRASILEIROS: OS CASOS DAS CONSTITUIÇÕES DE 1824 E 1988}

O presente estudo está limitado à análise dos Títulos de $1^{0}$ ao $3^{\circ}$ das Constituições brasileiras de 1824 e 1988.

OS SUBSTANTIVOS DA CONSTITUIÇÃO DE 1824 QUE SE REPETEM NA CONSTITUIÇÃO DE 1988

Propõe-se nessa seção apresentar os resultados da pesquisa atendendo ao objetivo específico de identificar os substantivos da Constituição de 1824 que se repetem na Constituição de 1988. Além disso, os substantivos identificados na Constituição de 1824 foram usadas para a realização do processo de busca na Constituição de 1988 para verificar se os mesmos se repetiam nessa Constituição. Aqueles que se repetiram no segundo caso, foram dispostos lado a lado no Quadro 1 abaixo, visando a comparação da frequência em que cada substantivo apareceu nas duas épocas distintas.

Quadro 1 - Frequência dos substantivos que se repetem nos textos constitucionais de 1824 e 1988.

\begin{tabular}{|l|c|c||l|c|c|}
\hline \multirow{2}{*}{ Substantivos } & \multicolumn{2}{|c|}{ Frequência na Constituição } & \multirow{2}{*}{ Substantivos } & \multicolumn{2}{c|}{ Frequência na Constituição } \\
\cline { 2 - 3 } & $\mathbf{1 8 2 4}$ & $\mathbf{1 9 8 8}$ & & $\mathbf{1 8 2 4}$ & $\mathbf{1 9 8 8}$ \\
\hline Assembléa & 2 & 2 & Licença & 1 & 3 \\
\hline Associação & 1 & 3 & Mãi & 1 & 4 \\
\hline Bem & 1 & 5 & Nome & 1 & 1 \\
\hline Brazil & 10 & 16 & Pai & 4 & 4 \\
\hline Casa & 1 & 2 & Poder & 17 & 11 \\
\hline Cidadãos & 4 & 2 & Povos & 2 & 3 \\
\hline Constituição & 2 & 1 & Principio & 1 & 3 \\
\hline Culto & 1 & 2 & Prisão & 1 & 5 \\
\hline Direito & 3 & 28 & Residencia & 1 & 3 \\
\hline Emprego & 1 & 2 & Representação & 1 & 3 \\
\hline Estado & 2 & 16 & Serviço & 1 & 6 \\
\hline Estrangeiro & 6 & 11 & Sentença & 2 & 3 \\
\hline Filho & 2 & 4 & Territorio & 2 & 2 \\
\hline Garantia & 1 & 10 & União & 1 & 2 \\
\hline Harmonia & 1 & 1 & \multicolumn{2}{|l}{} \\
\hline
\end{tabular}

Fonte: Elaborado pelas autoras.

A INCIDÊNCIA DE MUDANÇAS SEMÂNTICAS E PRAGMÁTICAS NOS SUBSTANTIVOS DA CONSTITUIÇÃO DE 1824 QUE SE REPETEM NA CONSTITUIÇÃO DE 1988 
Comparando a frequência que o substantivo aparece na constituição de 1824 e depois na constituição de 1988, pode-se analisar os tipos possíveis de mudança na língua escrita nos dois textos jurídicos.

Considerando a contagem dos substantivos repetidos nas duas constituições, limitando-se aos Títulos de $1^{\circ}$ ao $3^{\circ}$, foram encontradas 29 palavras no total. Desse total, em torno de $70 \%$ sofreram mudanças de significado, de contexto ou de uso. As mudanças semânticas identificadas foram por ampliação ou mudança do significado das palavras. As mudanças pragmáticas foram entendidas como mudanças de contexto e do uso da palavra. Estas informações estão sistematizadas no Quadro 2.

Observou-se que a maior incidência de mudanças ocorreu por ampliação do uso das palavras, portanto mudanças semânticas. Interessante ressaltar o caso da palavra "poder". Houve uma ampliação do uso da palavra, porém, ao mesmo tempo, houve uma redução da incidência dessa palavra. Cogita-se que o contexto de uso da palavra se ampliou da esfera do poder de governo para a esfera de poder do povo, uma vez que a constituição de 1988 escreve no seu caput que "todo poder emana do povo".

Quadro 2 - Incidência de mudanças semânticas e pragmáticas nos substantivos que se repetem nas constituições de 1824 e 1988 


\begin{tabular}{|c|c|c|c|c|}
\hline $\begin{array}{l}\text { Substantivos } \\
\text { Repetidos } \\
1824 \text { e } 1988\end{array}$ & $\begin{array}{l}\text { Frequência } \\
\text { na CF/1988 }\end{array}$ & $\begin{array}{l}\text { \% variação } \\
\text { na CF/1988 }\end{array}$ & & $\begin{array}{c}\text { Tipo de } \\
\text { Mudança }\end{array}$ \\
\hline Assembléa & 10 & $80 \%$ & Semântica & $\begin{array}{l}\text { Ampliação do significado: } \\
1824 \text { - Assembléria Geral (deputados e senadores) } \\
1988 \text { - Assembléia Constituinte; Assembléia de trabalhadores (sindicatos) }\end{array}$ \\
\hline Associação & 4 & $75 \%$ & Semântica & $\begin{array}{l}\text { Mudança do significado: } \\
1824 \text { - união de interesses políticos } \\
1988 \text { - ato do cidadão associar-se }\end{array}$ \\
\hline Bem & 5 & $80 \%$ & Semântica & $\begin{array}{l}\text { Ampliação do significado: } \\
1824 \text { - estado de bem-estar } \\
1988 \text { - um patrimômio material }\end{array}$ \\
\hline Brazil & 16 & $38 \%$ & Semântica & $\begin{array}{l}\text { Mudança do significado: } \\
1824 \text {-Império } \\
1988 \text { - República Federativa }\end{array}$ \\
\hline Casa & 2 & $50 \%$ & Semântica & $\begin{array}{l}\text { TVuaança do signimcado: } \\
1824 \text {-Local de culto religioso. } \\
1988 \text { - Residência; Parlamento Legislativo. }\end{array}$ \\
\hline Cidadãos & 2 & $-50 \%$ & Pragmática & $\begin{array}{l}\text { Mudança do uso: } \\
1824 \text { - direito de registro como brasileiro } \\
1988 \text { - direito de participar da vida política }\end{array}$ \\
\hline Constituição & 25 & $92 \%$ & Pragmática & $\begin{array}{l}\text { Mudança do uso: } \\
1824 \text { - Constituição política do império } \\
1988 \text { - Constituição do Estado de direito da federação; Constituição de uma Unidade } \\
\text { da Federação. }\end{array}$ \\
\hline Culto & 2 & $50 \%$ & Semântica & $\begin{array}{l}\text { Ampliação do significado: } \\
1824 \text { - liturgia } \\
1988 \text { - locais de culto. }\end{array}$ \\
\hline Direito & 28 & $89 \%$ & Semântica & $\begin{array}{l}\text { Ampliação do significado: } \\
1824 \text { - registro como brasileiro; políticos. } \\
1988 \text { - direito individual. }\end{array}$ \\
\hline Emprego & 2 & $50 \%$ & & sem mudança \\
\hline Estado & 16 & $88 \%$ & Semântica & $\begin{array}{l}\text { Amplaaçao do signiticado: } \\
1824 \text { - Entidade territorial e de poder governamental. } \\
1988 \text { - Forma de governo democrático; Unidade da Federação; }\end{array}$ \\
\hline Estrangeiro & 11 & $45 \%$ & & sem mudança \\
\hline Filho & 4 & $50 \%$ & Pragmática & $\begin{array}{l}\text { Mudança do uso: } \\
1824 \text { - legítimo; ilegítimo } \\
1988 \text { - filho registrado como tal por um adulto. }\end{array}$ \\
\hline Garantia & 10 & $90 \%$ & Semântica & $\begin{array}{l}\text { Ampllaçao do signifıcado: } \\
1824 \text { - política governamental. } \\
1988 \text {-de direitos individuais; material; de valor real; jurídica; proteção do Estado. }\end{array}$ \\
\hline Harmonia & 1 & $0 \%$ & & sem mudança \\
\hline Licença & 3 & $67 \%$ & Pragmática & $\begin{array}{l}\text { Mudança do uso: } \\
1824 \text { - autorização } \\
1988 \text {-afastamento do trabalho }\end{array}$ \\
\hline Mãi & 2 & $50 \%$ & & sem mudança \\
\hline Nome & 1 & $0 \%$ & & sem mudança \\
\hline Pai & 4 & $0 \%$ & Pragmática & $\begin{array}{l}\text { Mudança do uso: } \\
1824 \text { - legítimo; ilegítimo } \\
1988 \text { - tem um filho registrado em seu nome. }\end{array}$ \\
\hline Poder & 11 & $-55 \%$ & Semântica & $\begin{array}{l}\text { Ampliação do significado: } \\
1824 \text { - político; os Poderes (divisão de encargos do Estado) } \\
1988 \text {-capacidade individual de ação. }\end{array}$ \\
\hline Povos & 3 & $33 \%$ & & sem mudança \\
\hline Principio & 3 & $67 \%$ & & sem mudança \\
\hline Prisão & 5 & $80 \%$ & & sem mudança \\
\hline Residencia & 3 & $67 \%$ & & sem mudança \\
\hline Representaçãc & 3 & $67 \%$ & Semântica & $\begin{array}{l}\text { Ampliação do significado: } \\
1824 \text { - política da nação. } \\
1988 \text { - do povo; ato jurídico }\end{array}$ \\
\hline Serviço & 6 & $83 \%$ & Semântica & $\begin{array}{l}\text { Ampliação do significado: } \\
1824 \text { - trabalho } \\
1988 \text {-serviço militar }\end{array}$ \\
\hline Sentença & 3 & $33 \%$ & & sem mudança \\
\hline Territorio & 2 & $0 \%$ & Semântica & $\begin{array}{l}\text { Ampliação do significado: } \\
1824 \text { - área de extensão sob o controle do Estado e de outras entidades políticas. } \\
1988 \text { - Unidade da Federação }\end{array}$ \\
\hline União & 2 & $50 \%$ & Semântica & $\begin{array}{l}\text { Ampliação do significado: } \\
1824 \text { - reunião de unidades territorriais e entidades políticas. } \\
1988 \text { - Unidade da Federação }\end{array}$ \\
\hline
\end{tabular}

Fonte: Elaborado pelas autoras. 


\section{CONSIDERAÇÕES FINAIS}

Conclusivamente, 0 enfoque desse estudo relaciona-se às transformações da língua escrita nos textos constitucionais brasileiros de 1824 e 1988. Com a finalidade de identificar as mudanças de significado do substantivo, atentando para a sua ampliação ou restrição, objeto de estudo da semântica; bem como o uso das palavras, estudo da pragmática.

Em atendimento aos objetivos específicos, foi feita a verificação dos substantivos da Constituição de 1824 que se repetiam na Constituição de 1988. Os resultados mostraram que 29 substantivos se repetiam na segunda constituição, limitando-se a contagem aos Títulos $1^{\circ}, 2^{\circ}$ e $3^{\circ}$. Posteriormente, foi verificada a incidência de mudanças semânticas e pragmáticas que ocorreram nos substantivos que se repetem nas duas constituições, bem como foi quantificada a frequência em que cada substantivo aparecia em cada documento analisado. De posse desses números, foram analisadas mudanças em que cada palavra sofreu.

Os resultados desse estudo confirmam os pressupostos teóricos estudados de que a língua se modifica através do tempo, seja no seu contexto ou seja nas mudanças de significado e de uso.

\section{REFERÊNCIAS}

BRASIL. PALÁCIO DO PLANALTO. Constituição Política do Império do Brazil de 25 de março de 1824. Disponível em: http://www4.planalto.gov.br/legislacao. Acesso em: 15 de abril de 2015.

Constituição da República Federativa do Brasil de 1988. Disponível em: http://www4.planalto.gov.br/legislacao. Acesso em: 15 de abril de 2015.

DUCROT, O. Estruturalismo e linguistica. $2^{2}$ ed. São Paulo: Cultrix. 1971.

FARACO, C. A. Linguística histórica. São Paulo: Ática. 1991.

FIORIN, J. L. Introdução à linguística: II princípios de análise. São Paulo: Contexto. 2004.

KLEIBER. Contexte, où es-tu?. Revue de Sémantique et Pragmatique. 1: 65-79

LYONS, J. Linguagem e lingúistica:uma introdução. Rio de Janeiro: LTC. 1987.

MAGDALENO, F.S. O território nas constituições republicanas brasileiras. Investigaciones Geográficas. N. 57, p. 114-132. 2005.

MARQUES, M. H. D. Iniciação à semântica. Rio de Janeiro: Jorge Zahar. 2003. 
MARTIN, R. Para entender a linguística: epistemologia elementar de uma disciplina. São Paulo: Parábola. 2003.

MOURA, H. M. M. Significação e contexto: uma introdução a questões de semântica e pragmática. Florianópolis: Insular. 1999.

MUSSALIM, F., BENTES, A. C. Introdução à linguística: domínio e fronteiras. Vol. 2. $3^{\mathrm{a}}$ ed. São Paulo: Cortez. 2003.

SAUSSURE, F. Curso de linguística geral. 26ª ed. São Paulo: Cultrix, 2004. . Curso de lingüística geral. São Paulo: Cultrix, 1969. 